\title{
Enzymatic Synthesis of Aromatic Polyesters by Lipase-Catalyzed Polymerization of Dicarboxylic Acid Divinyl Esters and Glycols
}

\author{
Hiroshi Uyama, Shigeru Yaguchi, ${ }^{*}$ and Shiro Kobayashi ${ }^{\dagger}$ \\ Department of Materials Chemistry, Graduate School of Engineering, Kyoto University, \\ Kyoto 606-8501, Japan \\ * Department of Materials Chemistry, Graduate School of Engineering, Tohoku University, \\ Sendai 980-8579, Japan
}

(Received November 27, 1998)

\begin{abstract}
Polyesters containing aromatic moiety in the main chain have been synthesized by enzymatic polymerization of dicarboxylic acid divinyl esters and glycols under mild reaction conditions. Divinyl esters of isophthalic acid, terephthalic acid, and p-phenylene diacetic acid, were used as new monomer for the enzymatic polymerization. Effects of the polymerization conditions were systematically investigated in the polymerization of divinyl isophthalate and 1,6-hexanediol. Candida antarctica lipase afforded the polymer of the highest molecular weight. Methylene chain length of the glycol affected the polymer yield and molecular weight. Divinyl terephthalate was enzymatically polymerized under the similar reaction conditions, yielding the polymer of lower molecular weight. Enzymatic polymerization of divinyl sebacate and $p$-xylylene glycol also afforded the aromatic polyester.

KEY WORDS Enzymatic Polymerization / Lipase / Aromatic Polyester / Divinyl Ester / Polycondensation /
\end{abstract}

Aromatic polyesters, typically poly(ethylene terephthalate) (PET) and poly(butylene terephthalate) (PBT), are widely used in various fields since they have excellent properties, e.g., high thermal and chemical stabilities. ${ }^{1,2}$ These polymers are industrially produced at high temperature under reduced pressure. Since PET and PBT are not environmentally benign due to their low biodegradability, aliphatic and aromatic ester copolymers have been developed as new biodegradable engineering plastics. However, their synthesis also involved severe reaction conditions (high temperature and/or reduced pressure).

Recently, hydrolase-catalyzed polymerizations have received much attention as environmentally friendly methodology of polyester syntheses owing to non-toxic enzyme catalyst and mild reaction conditions. ${ }^{3-7}$ In some cases, lipase showed unique catalytic behaviors for the polyester syntheses in comparison with those of conventional chemical catalysts. Lipase induced the ring-opening polymerization of small- and medium-size lactones as well as macrolides (12-, 13-, 16-, and 17-membered lactones).$^{8-17}$ Using traditional chemical catalysts, the macrolides showed much lower reactivity and polymerizability than $\varepsilon$-caprolactone (7-membered lactone, $\varepsilon$-CL) due to their lower ring strain. ${ }^{18,19}$ However, they were enzymatically polymerized much faster than $\varepsilon$-CL, probably due to the stronger recognition of the macrolide by lipase. ${ }^{13-17}$

In lipase-catalyzed acylation for synthesis of functional organic products, vinyl esters have been often used as acylating agents because the irreversible tautomerization of the leaving vinyl alcohol group to acetaldehyde afforded the desired product in high yields. ${ }^{20,21} \mathrm{We}$ reported that divinyl adipate was superior to the corresponding diacid or dialkyl ester for the enzymatic synthesis of polyester. ${ }^{22}$ Afterwards, several examples of the enzymatic polymerizations using divinyl esters were

† To whom correspondence should be addressed. reported. $^{23-25}$ Very recently, we have found that the lipase-catalyzed polymerization of divinyl sebacate and glycerol proceeded regioselectively to give the soluble polyester mainly consisting of 1,3-diacylated structure of glycerol. ${ }^{26}$ Vinyl ester derivatives also acted as an efficient terminator of enzymatic ring-opening polymerization of lactones; facile single-step production of polyester macromonomers and telechelics was achieved by lipase-catalyzed polymerization of 13-membered lactone in the presence of vinyl esters. ${ }^{27-29}$

We have performed the systematic investigation on the effects of the reaction parameters in the lipase-catalyzed polymerization of dicarboxylic acid divinyl esters and $\alpha, \omega$-glycols, yielding aliphatic polyesters with different methylene chain length. ${ }^{30}$ This study deals with enzymatic synthesis of polyesters having an aromatic moiety in the main chain from divinyl esters and glycols (Scheme 1). Relevant to this study, there are two reports available on the enzymatic synthesis of aromatic polyesters. One is the protease-catalyzed polymerization of diethyl terephthalate and glycols to give the corresponding oligoesters with molecular weight from 400 to $1000 .^{31}$
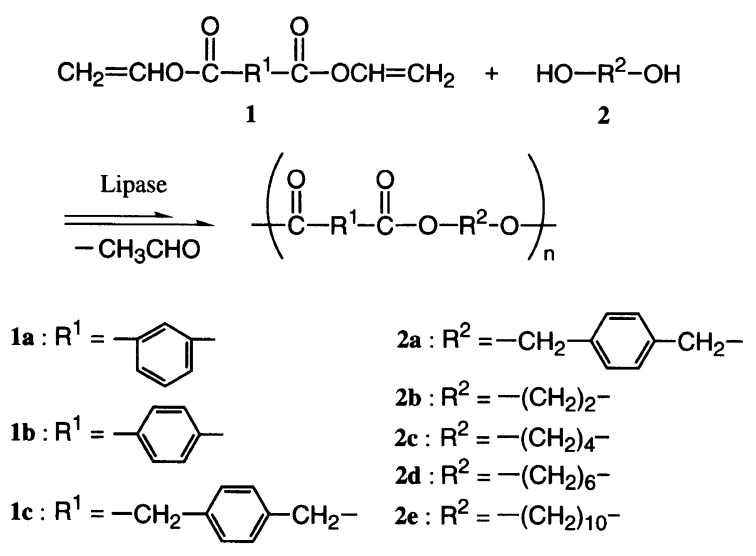

1d : $\mathrm{R}^{1}=-\left(\mathrm{CH}_{2}\right)_{8}^{-}$ 
Table I. Enzyme screen for polycondensation of $\mathbf{1 a}$ and $\mathbf{2} \mathbf{d}^{\mathrm{a}}$

\begin{tabular}{|c|c|c|c|c|}
\hline Entry & Catalyst & $\frac{\text { Yield }^{\mathbf{b}}}{\%}$ & $M_{n}^{\mathrm{c}}$ & $M_{w} / M_{n}^{\mathrm{c}}$ \\
\hline 1 & Lipase CA & 74 & 5500 & 1.6 \\
\hline 2 & Lipase CC & 0 & & \\
\hline 3 & Lipase MM & 40 & 2600 & 1.2 \\
\hline 4 & Lipase PC & 13 & 2000 & 1.1 \\
\hline 5 & Lipase PF & 36 & 2900 & 1.5 \\
\hline 6 & PPL & 0 & & \\
\hline 7 & ${ }^{\mathrm{d}}$ & 0 & & \\
\hline
\end{tabular}

a Polymerization of $1 \mathbf{a}$ and $\mathbf{2 d}$ (each $1.0 \mathrm{mmol}$ ) using lipase catalyst $(100 \mathrm{mg})$ in heptane $(5.0 \mathrm{~mL})$ at $60^{\circ} \mathrm{C}$ for $48 \mathrm{~h}$. ${ }^{\mathrm{b}}$ Methanol-insoluble part. ${ }^{\mathrm{c}}$ Determined by SEC. ${ }^{\mathrm{d}}$ Control experiment.

The other is synthesis of poly(1,6-hexanediyl isophthalate) and poly(1,6-hexanediyl terephthalate) from the corresponding dimethyl esters by using lipase catalyst, which involved a nitrogen bubbling procedure for the removal of methanol formed during the polymerization. ${ }^{32}$

\section{RESULTS AND DISCUSSION}

In this study, four monomers containing an aromatic moiety, divinyl isophthalate (1a), divinyl terephthalate (1b), divinyl $p$-phenylene diacetate (1c), and $p$-xylylene glycol (2a), were used as new monomer of enzymatic polymerizations.

\section{Enzymatic Polymerization of Divinyl Isophthalate and $\alpha, \omega$-Alkylene Glycols \\ The polymerization of divinyl isophthalate (1a) with} 1,6-hexanediol (2d) was carried out by using six lipases of different origin as catalyst in heptane at $60^{\circ} \mathrm{C}$ for $48 \mathrm{~h}$ (Table I). The catalysts used were lipases derived from Candida antarctica (lipase CA), Candida cylindracea (lipase CC), Mucor miehei (lipase MM), Pseudomonas cepacia (lipase PC), Pseudomonas fluorescens (lipase PF), and porcine pancreas (PPL), which showed high catalytic activity for the lactone polymerizations. ${ }^{8,13-17}$ Lipases $\mathrm{CA}$ and $\mathrm{MM}$ are granular immobilized enzymes and the others are crude powdery ones. In most cases, the monomer was quantitatively consumed, however, the yield was not high due to the loss of the oligomers during the purification procedure. The molecular weight of the polymer was estimated by size exclusion chromatographic (SEC) analysis using tetrahydrofuran (THF) eluent.

Active were lipases CA, MM, PC, and PF for the present polymerization, which also efficiently catalyzed the polymerization of divinyl sebacate (1d) and 1,4-butanediol (2c). ${ }^{30}$ On the other hand, no polymeric materials were obtained in using lipase CC and PPL. Lipase CA showed the highest catalytic activity; the yield and molecular weight of the polymer were the largest (entry 1). In the polymerization without enzyme (control experiment), the monomers were recovered unchanged (entry 7). These results indicate that the present polymerization proceeded through the enzyme catalysis and the polymerization behaviors depended on the lipase origin. In the subsequent experiments, therefore, lipase
Table II. Enzymatic polymerization of $1 \mathbf{a}$ and $\mathbf{2}^{\mathbf{a}}$

\begin{tabular}{|c|c|c|c|c|c|c|}
\hline \multirow[t]{2}{*}{ Entry } & \multirow[t]{2}{*}{ Glycol } & \multirow[t]{2}{*}{ Solvent } & \multirow{2}{*}{$\begin{array}{c}\begin{array}{c}\text { Temper- } \\
\text { ature }\end{array} \\
{ }^{\circ} \mathrm{C}\end{array}$} & \multirow{2}{*}{$\frac{\text { Yield }^{\mathrm{b}}}{\%}$} & \multirow{2}{*}{$M_{n}^{\mathrm{c}}$} & \multirow{2}{*}{$M_{w} / M_{n}^{\mathrm{c}}$} \\
\hline & & & & & & \\
\hline 1 & $\mathbf{2 b}$ & Heptane & 60 & 0 & & \\
\hline 2 & $2 c$ & Heptane & 60 & 60 & 1500 & 1.2 \\
\hline 3 & 2d & Acetonitrile & 60 & 0 & & \\
\hline 4 & 2d & Cyclohexane & 60 & 72 & 5300 & 1.8 \\
\hline 5 & 2d & Heptane & 45 & 42 & 2500 & 1.5 \\
\hline 6 & 2d & Heptane & 60 & 74 & 5500 & 1.6 \\
\hline 7 & 2d & Heptane & 75 & 66 & 4200 & 1.8 \\
\hline 8 & 2d & Isooctane & 60 & 73 & 4400 & 1.7 \\
\hline 9 & 2d & Tetrahydrofuran & 60 & 0 & & \\
\hline 10 & 2d & Toluene & 60 & 71 & 2000 & 1.4 \\
\hline 11 & $2 e$ & Heptane & 60 & 54 & 7200 & 2.1 \\
\hline
\end{tabular}

${ }^{\text {a }}$ Polymerization of $\mathbf{1 a}$ and $\mathbf{2}$ (each $1.0 \mathrm{mmol}$ ) using lipase CA catalyst $(100 \mathrm{mg})$ in organic solvent $(5.0 \mathrm{~mL})$ for $48 \mathrm{~h}$. ${ }^{\mathrm{b}}$ Methanol-insoluble part. ${ }^{\mathrm{c}}$ Determined by SEC.

CA is mainly used as catalyst.

The polymer structure was confirmed by ${ }^{1} \mathrm{H}$ and ${ }^{13} \mathrm{C}$ NMR spectroscopies. In all cases, the desired product was obtained and peaks due to the units of the vinyl polymer from 1 were not detected. Besides the main peaks, there were small peaks due to $\alpha$-methylene moiety of the terminal hydroxyl group: a triplet peak at $\delta 3.7$ in ${ }^{1} \mathrm{H}$ NMR spectrum and a peak at $\delta 62$ in that of ${ }^{13} \mathrm{C}$ NMR. Peaks of the vinyl ester were not observed, suggesting that the hydrolysis of the terminal vinyl ester occurred during the polymerization.

Effects of the polymerization conditions were systematically investigated in the polymerization of divinyl isophthalate and 1,6-hexanediol using lipase CA catalyst (Table II). At first, the polymerization was carried out in various anhydrous organic solvents at $60^{\circ} \mathrm{C}$. Hydrocarbons, cyclohexane, heptane, and isooctane, provided the polymer with molecular weight of $c a .5 \times 10^{3}$ in good yields (entries 4, 6, and 8), indicating hydrophobic solvents were suitable for the present polymerization. Similar results were obtained in the enzymatic synthesis of aliphatic polyesters from divinyl esters. ${ }^{30}$ The polymerization in toluene afforded the polymer in a moderate yield, however, the molecular weight of the resulting polymer was relatively low (entry 10). It is to be noted that toluene afforded no polymeric materials from a combination of $\mathbf{1 d}$ and $\mathbf{2 c} .^{30}$ No polymers were obtained in acetonitrile and THF (entries 3 and 9). This may be due to the inactivation of the enzyme in polar organic solvents.

Polymerization temperature also affected the polymerization results. In the temperature range from $45^{\circ} \mathrm{C}$ to $75^{\circ} \mathrm{C}$ (entries 5-7), yield and molecular weight of the polymer were the highest at $60^{\circ} \mathrm{C}$ (entry 6). These data are in contrast with those in the polymerization of $\mathbf{1 d}$ and $2 \mathbf{c}$; the polymerization at $45^{\circ} \mathrm{C}$ afforded the best results. $^{30}$ This may be due to the difference of the enzymatic reactivity between divinyl esters of aromatic and aliphatic diacids.

Next, effects of the chain length in $\alpha, \omega$-alkylene glycols $(\mathbf{2 b}-\mathbf{2 e})$ were examined. The polymerization of ethylene glycol (2b) with 1a did not produce the polymer (entry 1). From 1,4-buntanediol (2c), 1,6-hexanediol (2d), and 
Table III. Lipase CA-catalyzed polycondensation of $\mathbf{1 b}$ and $\mathbf{2}^{\mathbf{a}}$

\begin{tabular}{ccccc}
\hline Entry & Glycol & \multicolumn{1}{c}{ Yield $^{\mathrm{b}}$} & & \\
\cline { 3 - 3 } & & $\%$ & $M_{n}{ }^{\mathrm{c}}$ & $M_{w} / M_{n}{ }^{\mathrm{c}}$ \\
\hline 1 & $\mathbf{2 b}$ & $<5$ & & \\
2 & $\mathbf{2 c}$ & $34^{\mathbf{d}}$ & 1100 & 1.1 \\
3 & $\mathbf{2 d}$ & 72 & 2300 & 1.3 \\
4 & $\mathbf{2 e}$ & 58 & 2000 & 1.3 \\
\hline
\end{tabular}

a Polymerization of $\mathbf{1 b}$ and $\mathbf{2}$ (each $1.0 \mathrm{mmol}$ ) using lipase CA catalyst $(100 \mathrm{mg})$ in diisopropyl ether $(5.0 \mathrm{~mL})$ at $60^{\circ} \mathrm{C}$ for $48 \mathrm{~h}$. ${ }^{\mathrm{b}}$ Methanolinsoluble part. ${ }^{\mathrm{c}}$ Determined by SEC. ${ }^{\mathrm{d}}$ Diethyl ether-insoluble part.

Table IV. Lipase CA-catalyzed polycondensation of $1 \mathbf{c}$ and $\mathbf{2}^{\mathrm{a}}$

\begin{tabular}{|c|c|c|c|c|}
\hline Entry & Glycol & $\frac{\text { Yield }^{\mathrm{b}}}{\%}$ & $M_{n}^{\mathrm{c}}$ & $M_{w} / M_{n}^{\mathrm{c}}$ \\
\hline 1 & $2 \mathbf{b}$ & 34 & 1800 & 1.2 \\
\hline 2 & $2 c$ & 43 & 4400 & 1.4 \\
\hline 3 & $2 d$ & 44 & 6000 & 1.4 \\
\hline 4 & $2 e$ & 54 & 5800 & 1.8 \\
\hline
\end{tabular}

${ }^{\text {a }}$ Polymerization of $\mathbf{1 c}$ and $\mathbf{2}$ (each $1.0 \mathrm{mmol}$ ) using lipase CA catalyst $(100 \mathrm{mg})$ in heptane $(5.0 \mathrm{~mL})$ at $60^{\circ} \mathrm{C}$ for $48 \mathrm{~h}$. ${ }^{\mathrm{b}}$ Methanol-insoluble part. ${ }^{\mathrm{c}}$ Determined by SEC.

1,10-decanediol (2e), the polymer formation was observed. The polymer yield was the highest in using $\mathbf{2 d}$ (entry 6) and 2e afforded the highest molecular weight (entry 11).

\section{Enzymatic Synthesis of Polyesters from Other Aromatic Monomers}

Terephthalic acid divinyl ester (1b) was also polymerized under the similar reaction conditions of $\mathbf{1 a}$ (Table III). From a combination of $\mathbf{1 b}$ and $\mathbf{2} \mathbf{b}$, the polymer yield was very low (entry 1), whereas the polymer was obtained from other glycols in moderate yields. The polymer yield was the highest in using $2 \mathbf{d}$ as glycol monomer. A similar tendency was observed in the polymerization using 1a (Table II). The polymer molecular weight was lower than that from 1a. This is due to the lower solubility of the polymer having the parasubstituted diester structure than that with the metasubstituted structure. Polymer structure was confirmed by ${ }^{1} \mathrm{H}$ NMR spectroscopy. Besides main peaks of the polyester, there was a characteristic triplet peak at $\delta 3.7$ due to the $\alpha$-methylene protons of the terminal hydroxy group. No peaks due to the vinyl ester group were detected.

The polymerization of divinyl $p$-phenylene diacetate (1c) with glycols proceeded in the presence of lipase CA (Table IV). The polymerization of $\mathbf{1 c}$ and ethylene glycol (2b) afforded the polymer with relatively low molecular weight (entry 1), on the other hand, the polymer from 2b was not obtained in using aromatic diacid divinyl esters (1a and 1b). The larger the methylene chain length of $\mathbf{2}$, the higher the polymer yield. In using $\mathbf{2 d}$ as glycol monomer, the highest molecular weight was achieved (entry 3).

Another approach to synthesize aromatic polyesters is use of aromatic diols as monomer. However, lipasecatalyzed polymerization of divinyl sebacate with dihy-
Table V. Lipase CA-catalyzed polycondensation of $\mathbf{1 d}$ and $\mathbf{2} \mathbf{a}^{\mathbf{a}}$

\begin{tabular}{clccc}
\hline & & \multicolumn{2}{c}{ Yield $^{\mathrm{b}}$} & \\
\cline { 3 - 3 } Entry & Catalyst & $M_{n}{ }^{\mathrm{c}}$ & $M_{w} / M_{n}{ }^{\mathrm{c}}$ \\
& & $\%$ & & \\
\hline 1 & Lipase CA & 41 & 6200 & 1.7 \\
2 & Lipase MM & 61 & 2600 & 1.3 \\
3 & Lipase PC & 74 & 4000 & 1.5 \\
4 & Lipase PF & 72 & 4200 & 1.5
\end{tabular}

${ }^{a}$ Polymerization of $\mathbf{1 c}$ and $\mathbf{2}$ (each $2.0 \mathrm{mmol}$ ) using lipase CA catalyst $(100 \mathrm{mg})$ in heptane $(5.0 \mathrm{~mL})$ at $75^{\circ} \mathrm{C}$ for $48 \mathrm{~h} .{ }^{b}$ Methanol-insoluble part. ${ }^{\mathrm{c}}$ Determined by SEC.

droxybenzenes, catechol, resorcinol, and hydroquinone, did not take place. Thus, $p$-xylylene glycol (2a) was employed as new monomer in the lipase-catalyzed polymerization of 1d (Table V). Lipases showing the high catalytic activity for the polymerization of $\mathbf{1 a}$ and $\mathbf{2 d}$ (Table I) also afforded the polymer from a combination of 1d and 2a. In using Pseudomonas family lipases (lipases PC and PF), the polymer yield was high (entries 3 and 4). The polymerization catalyzed by lipase CA produced the polymer of the highest molecular weight (entry 1).

\section{CONCLUSION}

Facile synthesis of polyesters having aromatic moiety in the main chain was achieved by the lipase-catalyzed polymerization of divinyl esters and glycols. The aromatic polyesters were synthesized by using new monomers of divinyl isophthalate, divinyl terephthalate, divinyl $p$-phenylene diacetate, and $p$-xylylene glycol under mild reaction conditions. In most cases, Candida antarctica lipase showed the high catalytic activity for the present polymerization to give the polymers with the molecular weight of several thousands.

Further investigations on enzymatic synthesis of polyesters from other vinyl ester monomers are under way in our laboratory.

\section{EXPERIMENTAL}

\section{Materials}

Divinyl sebacate (1d) was kindly donated by Shin-etsu Chemical Co. Lipases CA and MM were gifts from Novo Nordisk Bioindustry, Ltd. Lipase CC and PPL were purchased from Biocatalysts, Ltd. and Sigma Chemical Co., respectively. Lipases $\mathrm{PC}$ and PF were donated by Amano Pharmaceutical Co. These enzyme catalysts were used as received. Liquid monomers and polymerization solvents were stored over freshly activated type 4 molecular sieves. Other reagents were used without further purification.

\section{Preparation of Divinyl Isophthalate 33}

A mixture of isophthalic acid $(15 \mathrm{~g}, 90 \mathrm{mmol})$, vinyl acetate $(39 \mathrm{~g}, 450 \mathrm{mmol})$, palladium (II) acetate $(1.0 \mathrm{~g}$, $4.5 \mathrm{mmol})$, and potassium acetate $(0.88 \mathrm{~g}, 9.0 \mathrm{mmol})$ was dissolved in $60 \mathrm{~mL}$ of $N, N$-dimethylformamide (DMF). The mixture was stirred at $45^{\circ} \mathrm{C}$ for $24 \mathrm{~h}$ under argon. The reaction mixture was filtrated through Celite, followed by concentration of the filtrate under reduced 
pressure. The product was purified by sublimation at $80^{\circ} \mathrm{C}$ under $400 \mathrm{~Pa}$, yielding $8.2 \mathrm{~g}$ of divinyl isophthalate (yield $42 \%)$. ${ }^{1} \mathrm{H}$ NMR $\left(\mathrm{CDCl}_{3}\right) \delta 4.8$ and $5.2(\mathrm{~d}$, $\left.\mathrm{CH}_{2}=\mathrm{CHO}-, 4 \mathrm{H}\right), 7.5\left(\mathrm{q}, \mathrm{CH}_{2}=\mathrm{CHO}-, 2 \mathrm{H}\right), 7.6,8.3$, 8.8 (Ar, 4H).

Terephthalic acid and $p$-phenylene diacetic acid divinyl esters were synthesized by the similar procedure.

\section{Lipase-Catalyzed Polymerization of Dicarboxylic Acid Divinyl Esters and Glycols}

A typical run was as follows (entry 1 in Table I). Divinyl isophthalate $(0.22 \mathrm{~g}, 1.0 \mathrm{mmol})$ and 1,6 -hexanediol $(0.12 \mathrm{~g}, 1.0 \mathrm{mmol})$ in $5.0 \mathrm{~mL}$ of heptane were placed in a dried test tube. Lipase CA $(100 \mathrm{mg})$ was added and the mixture was gently stirred at $60^{\circ} \mathrm{C}$. After $48 \mathrm{~h}$, $30 \mathrm{~mL}$ of chloroform was added to the reaction mixture. The lipase was removed by filtration and the filtrate was concentrated by evaporation under reduced pressure. A small amount of chloroform was added to the residue and the solution was poured into a large amount of methanol. The resulting precipitates were separated by filtration, following by drying in vacuo to give the polymer $\left(0.18 \mathrm{~g}, 74 \%\right.$ yield). ${ }^{1} \mathrm{H}$ NMR $\left(\mathrm{CDCl}_{3}\right) \delta 1.5$ (b, $\left.\mathrm{OCH}_{2} \mathrm{CH}_{2} \mathrm{CH}_{2}, 4 \mathrm{H}\right), 1.8\left(\mathrm{~b}, \mathrm{OCH}_{2} \mathrm{CH}_{2}, 4 \mathrm{H}\right), 4.3$ (b, $\left.\mathrm{OCH}_{2}, 4 \mathrm{H}\right), 7.5,8.1,8.6(\mathrm{Ar}, 4 \mathrm{H})$.

${ }^{1} \mathrm{H}$ NMR of polymer from $\mathbf{1 b}$ and $2 \mathbf{c}\left(\mathrm{CDCl}_{3}\right) \delta 1.5$ (b, $\left.\mathrm{OCH}_{2} \mathrm{CH}_{2} \mathrm{CH}_{2}, 4 \mathrm{H}\right), 1.8$ (b, $\left.\mathrm{OCH}_{2} \mathrm{CH}_{2}, 4 \mathrm{H}\right), 4.3$ (b, $\left.\mathrm{OCH}_{2}, 4 \mathrm{H}\right), 8.1$ (b, Ar, 4H).

\section{Measurements}

SEC analysis was carried out using a Tosoh SC8010 apparatus with a refractive index (RI) detector under the following conditions: TSKgel $\mathrm{G} 3000 \mathrm{H}_{\mathrm{HR}}$ column and THF eluent at a flow rate of $1.0 \mathrm{~mL} \mathrm{~min}^{-1}$. The calibration curves for SEC analysis were obtained using polystyrene standards. NMR spectra were recorded on a $270 \mathrm{MHz}$ JEOL JNM-EX270J spectrometer.

Acknowledgments. This work was supported by a Grant-in-Aid for Specially Promoted Research (No. 08102002) from the Ministry of Education, Science, Sports and Culture of Japan. We appreciate the gifts of lipases and divinyl sebacate from Amano Pharmaceutical Co., Novo Nordisk Bioindustry, Ltd., and Shin-etsu Chemical Co.

\section{REFERENCES AND NOTES}

1. S. A. Jabarin, "The Polymeric Materials Encyclopedia," J. C. Salamone, Ed., CRC Press, Boca Raton, FL, 1996, pp $6078-6085$.
2. N. Tsutsumi and M. Nagata, "The Polymeric Materials Encyclopedia," J. C. Salamone, Ed., CRC Press, Boca Raton, FL, 1996, pp 6110-6114.

3. S. Kobayashi, S. Shoda, and H. Uyama, Adv. Polym. Sci., 121 1 (1995).

4. S. Kobayashi, S. Shoda, and H. Uyama, "The Polymeric Materials Encyclopedia," J. C. Salamone, Ed., CRC Press, Boca Raton, FL, 1996, pp 2102-2107.

5. S. Kobayashi, S. Shoda, and H. Uyama, "Catalysis in Precision Polymerization," S. Kobayashi, Ed., John Wiley \& Sons, Chichester, 1997, Chapter 8.

6. R. A. Gross, D. L. Kaplan, and G. Swift, Ed., ACS Symp. Ser., 684 (1998).

7. S. Kobayashi, H. Uyama, and S. Namekawa, Polym. Degrad. Stab., 59, 195 (1998).

8. H. Uyama and S. Kobayashi, Chem. Lett., 1149 (1993).

9. D. Knani, A. L., Gutman, and D. H. Kohn, J. Polym. Sci., Polym. Chem. Ed., 31, 1221 (1993).

10. R. T. MacDonald, S. K. Pulapura, Y. Y. Svirkin, R. A. Gross, D. L. Kaplan, J. A. Akkara, G. Swift, and S. Wolk, Macromolecules, 28, 73 (1995).

11. S. Kobayashi, H. Uyama, S. Namekawa, and H. Hayakawa, Macromolecules, 31, 5655 (1998).

12. S. Matsumura, Y. Suzuki, K. Tsukada, K. Toshima, Y. Doi, and K. Kasuya, Macromolecules, 31, 6444 (1998).

13. H. Uyama, K. Takeya, and S. Kobayashi, Bull. Chem. Soc. Jpn., 68, 56 (1995)

14. H. Uyama, K. Takeya, N. Hoshi, and S. Kobayashi, Macromolecules, 28, 7046 (1995).

15. H. Uyama, H, Kikuchi, K. Takeya, and S. Kobayashi, Acta Polymerica, 47, 357 (1996)

16. H. Uyama, S. Namekawa, and S. Kobayashi, Polym. J., 29, 299 (1997).

17. S. Namekawa, H. Uyama, and S. Kobayashi, Proc. Jpn. Acad., 74B, 65 (1998).

18. R. Huisgen and H. Ott, Tetrahedron, 6, 253(1959).

19. R. Nomura, A. Ueno, and T. Endo, Macromolecules, 27, 620(1994).

20. K. Faber and S. Riva, Synthesis, 895 (1992).

21. J. Otera, Chem. Rev., 93, 1449 (1993).

22. H. Uyama and S. Kobayashi, Chem. Lett., 1687 (1994).

23. A. K. Chaudhary, E. J. Beckman, and A. J. Russell, J. Am. Chem. Soc., 117, 3728 (1995).

24. A. K. Chaudhary, E. J. Beckman, and A. J. Russell, Biotechnol. Bioeng., 55, 227 (1997).

25. A. K. Chaudhary, J. Lopez, E. J. Beckman, and A. J. Russell, Biotechnol. Prog., 13, 318 (1997).

26. H. Uyama, K. Inada, and S. Kobayashi, Macromol. Rapid Commun., in press.

27. H. Uyama, H. Kikuchi, and S. Kobayashi, Chem. Lett., 1047 (1995).

28. H. Uyama, H. Kikuchi, and S. Kobayashi, Bull. Chem. Soc. Jpn., 70, 1691 (1997)

29. S. Kobayashi and H. Uyama, Macromol. Symp., in press.

30. H. Uyama, S. Yaguchi, and S. Kobayashi, J. Polym. Sci., Polym. Chem. Ed., in press

31. H. G. Park, H. N. Chang, and J. S. Dordick, Biocatalysis, 11, 263 (1994).

32. G. Mezoul, T. Lalot, M. Brigodiot, and E. Marchal, Polym. Bull., 36, 541 (1998).

33. M. Lobell and M. P. Schneider, Synthesis, 375 (1994). 